\title{
PENENTUAN KECEPATAN PUTAR KIPAS ANGIN DAN INTENSITAS LAMPU DENGAN FUZZY LOGIC MAMDANI
}

\section{Determination Of Wind Fan Speed And Lamp Intensity With Mamdani Fuzzy Logic}

\author{
Chyquitha Danuputri, M.Kom, chyquitha@gmail.com ${ }^{1)}$ \\ ${ }^{1)}$ Teknik Informatika, Fakultas Teknik dan Desain, Universitas Bunda Mulia
}

\begin{abstract}
Intelligent systems are one of the most important branches of the computer world. Computers are expected to be able to solve various problems in the real world, not just a tool for doing calculations. To make this system, algorithms are needed that are in accordance with the problems faced so that they can solve or produce the decisions needed to solve these problems appropriately. Mamdani fuzzy logic algorithm is one of the algorithms that can be applied in intelligent systems. Fuzzzy mamdani algorithm, is one part of the Fuzzy Inference System which is useful for making the best conclusion or decision in an uncertain problem. This research focuses on the calculation of the fuzzy logic algorithm in providing answers to the uncertainties found in smart home systems used to control the speed of a fan and lights, while the factors that become uncertainty in controlling a fan are room temperature and humidity and For lamps, they have a factor of light intensity and time of the region, for these factors the researchers use the Huminity Guide Hygiene standard reference for humidity and the Regulation of the Minister of Health of the Republic of Indonesia Number 1077 / Menkes / Per / V 2011 concerning Guidelines for Air Sanitation in Home Spaces. Through this research, it can be seen that using the mamdani fuzzy logic algorithm can provide a result in the form of a decision to determine how fast a fan should rotate based on the temperature and humidity factors in the room as well as the level of light intensity that the lights must emit.
\end{abstract}

Keyword : fuzzy logic mamdani, smart system, artifical intelligence, fan control, light control

\begin{abstract}
ABSTRAK
Sistem cerdas merupakan salah satu cabang terpenting dalam dunia komputer. Komputer diharapkan untuk bisa menyelesaikan berbagai permasalahan didunia nyata bukan hanya sekedar alat untuk melakukan perhitungan. Untuk membuat sistem tersebut dibutuhkan algoritma-algoritma yang sesuai dengan permasalahan yang dihadapi sehingga dapat menyelesaikan atau menghasilkan suatu keputusan yang dibutuhkan untuk menyelesaikan permasalah tersebut dengan tepat. Algoritma fuzzy logic mamdani merupakan salah satu algoritma yang dapat diterapkan didalam sistem cerdas. Algoritma fuzzy mamdani, merupakan salah satu bagian dari Fuzzy Inference System yang berguna untuk melakukan penarikan kesimpulan atau suatu keputusan terbaik dalam permasalahan yang tidak pasti. Pada penelitian ini memfokuskan perhitungan dari algoritma fuzzy logic dalam memberikan jawaban atas ketidakpastian yang ditemukan pada sistem pintar rumah yang digunakan untuk mengkontrol kecepatan dari sebuah kipas angin dan lampu, adapun faktor-faktor yang menjadi ketidakpastian dalam mengkontrol sebuah kipas angin adalah suhu dan kelembapan ruangan serta untuk lampu memiliki faktor intensitas cahaya serta waktu daerah, untuk faktor tersebut peneliti menggunakan acuan standar Huminity Guide Higienis Indonesia untuk kelembapan dan Peraturan Menteri Kesehatan Republik Indonesia Nomor 1077/Menkes/Per/V/2011 tentang Pedoman Penyehatan Udara Dalam Ruang Rumah. Melalui penelitian ini, dapat diketahui dengan menggunakan algoritma fuzzy logic mamdani dapat memberikan sebuah hasil berupa keputusan untuk menentukan seberapa cepat sebuah kipas angin harus berputar berdasarkan faktor suhu dan kelembapan yang ada pada ruangan tersebut serta tingkat intensitas cahaya yang harus dikeluarkan lampu.
\end{abstract}

Kata Kunci: fuzzy logic mamdani, sistem cerdas, kecerdasan buatan, kontol kipas, kontrol cahaya 


\section{PENDAHULUAN}

Sistem cerdas merupakan salah satu cabang terpenting dalam dunia komputer. Komputer diharapkan untuk bisa menyelesaikan berbagai permasalahan didunia nyata bukan hanya sekedar alat untuk melakukan perhitungan[1]. Untuk menciptakan sebuah sistem pintar diperlukan penggunaan algoritma yang tepat sehingga nantinya sistem tersebut dapat menghasilkan sebuah hasil atau keputusan yang dapat menyelesaikan masalah yang dihadapi.

Algoritma fuzzy mamdani merupakan salah satu algoritma yang dapat diterapkan pada sebuah sistem cerdas. Algoritma fuzzy mamdani dapat memberikan sebuah kesimpulan atau keputusan akan suatu kondisi yang tidak pasti berdasarkan perhitungan faktor-faktor yang ada[2]. Oleh karena itu penelitian ini akan menerapkan perhitungan fuzzy mamdani pada contoh kasus sistem pintar rumah yang mengatur kecepatan kipas angin dan intensitas lampu.

Selain itu, penelitian ini diharapkan dapat memberikan wacana bahwa algoritma fuzzy logic mamdani dapat diterapkan untuk menarik keputusan dari suatu kondisi yang belum pasti dalam sistem cerdas rumah.

\section{METODE PENELITIAN}

Penelitian ini bertujuan untuk mengembangkan teori dalam metode pengambilan keputusan untuk menentukan seberapa cepat sebuah kipas angin harus berputar berdasarkan faktor suhu dan kelembapan yang ada pada ruangan tersebut serta tingkat intensitas cahaya yang harus dikeluarkan lampu. Berdasarkan tujuan dan ruang lingkup penelitian yang telah dibahas sebelumnya, penelitian ini merupakan jenis penelitian murni dan penelitian terapan. Penelitian murni adalah penelitian yang diperuntukan bagi pengembangan ilmu pengetahuan, bertujuan untuk mengembangkan teori atau menemukan teori baru, sedagkan penelitian terapan adalah penelitian yang hasilnya dapat langsung diterapkan untuk memecahkan permasalahan-permasalahan yang dihadapi (Moedjiono 2012).

Penerapan konsep penelitian ini akan diimplementasikan pada mikrokontroller yang nantinya dikembangkan menggunakan metode pengembangan sistem model prototipe, analisis dan perancangan sistem dengan pendekatan berorientasi objek.

\section{Metode Pengumpulan Data}

Metode pengumpulan data yang digunakan dalam penelitian ini adalah:

\section{Metode observasi}

Observasi adalah kegiatan pengamatan yang direncanakan, sistematis dan hasilnya dicatat serta diinterpretasikan dalam rangka memperoleh pemahaman tentang objek yang diamati[Sugiyono 2012].

Observasi yang dilakukan adalah pengamatan terhadap Algoritma fuzzy mamdani, merupakan salah satu bagian dari Fuzzy Inference System yang berguna untuk melakukan penarikan kesimpulan atau suatu keputusan terbaik dalam permasalahan yang tidak pasti guna dilakukan analisis lebih lanjut Sumber Data.

\section{Metode Studi Pustaka}

Metode pengumpulan data yang diperoleh dengan mempelajari, meneliti, dan membaca buku, jurnal, skripsi, tesis baik hardcopy maupun softcopy yang terdapat di internet yang berhubungan dengan sistem cerdas dan algoritma fuzzy mamdani.

Metode Mamdani sering juga dikenal dengan nama metode Max-Min. Metode ini diperkenalkan oleh 
Ebrahim Mamdani pada tahun 1975[3]. Metode Fuzzy Mamdani merupakan salah satu bagian dari Fuzzy Inference System yang berguna untuk penarikan kesimpulan atau suatu keputusan terbaik dalam permasalahan yang tidak pasti (DM.Sukandi, 2013). Penarikan kesimpulan dapat dibuat dengan memiliki minimal terdapat dua buah kaidah fuzzy. Untuk mendapatkan output, diperlukan 4 (empat) tahap :

\section{Pembentukan Himpunan Fuzzy}

Himpunan fuzzy merupakan suatu pengembangan lebih lanjut tentang konsep himpunan dalam matematika. Himpunan Fuzzy adalah rentang nilai-nilai. Masingmasing nilai mempunyai derajat keanggotaan (membership) antara 0 sampai dengan 1 , nilai 0 diartikan tidak termasuk anggota himpunan sedangkan nilai lebih dari $0 \quad$ merupakan anggota himpunan.

2. Aplikasi fungsi implikasi (aturan)

Pada Metode Mamdani, fungsi implikasi yang digunakan adalah Min yaitu mengambil nilai minimum berdasarkan aturan ke-i dan dapat dinyatakan dengan:

$\alpha i=\mu \mathrm{Ai}(\mathrm{x}) \cap \mu \mathrm{Bi}(\mathrm{x})=\min \{(\mathrm{x}), \mu \mathrm{B}(\mathrm{x})\}$ Keterangan:

$\alpha \dot{\mathrm{i}}=$ nilai minimum dari himpunan fuzzy $\mathrm{A}$ dan B pada aturan ke-i

$\mu \mathrm{Ai}(\mathrm{x})=$ derajat keanggotaan $\mathrm{x}$ dari himpunan fuzzy A pada aturan ke-i

$\mu \mathrm{Bi}(\mathrm{x})=$ derajat keanggotaan $\mathrm{x}$ dari himpunan fuzzy B pada aturan ke-i $\mu \mathrm{Ci}(\mathrm{x})=$ derajat keanggotaan konsekuen pada himpunan fuzzy $\mathrm{C}$ pada aturan ke-i.

\section{Komposisi aturan}

Tidak seperti penalaran monoton, apabila sistem terdiri-dari beberapa aturan,maka inferensi diperoleh dari kumpulan dan korelasi antar aturan. Ada 3 metode yang digunakan dalam melakukan inferensi sistem fuzzy, yaitu: max, additive dan probabilistik $O R$ (probor).

4. Penegasan (defuzzy)

Input dari proses defuzzifikasi adalah suatu himpunan fuzzy yang diperoleh dari komposisi aturan-aturan fuzzy, sedangkan output yang dihasilkan merupakan suatu bilangan pada domain himpunan fuzzy tersebut. Sehingga jika diberikan suatu himpunan fuzzy dalam range tertentu, maka harus dapat diambil suatu nilai crsip tertentu sebagai output.

\section{HASIL DAN PEMBAHASAN}

\section{Implementasi Kontrol Kipas}

Implementasi Kontrol Kipas dengan Fuzzy mamdani adalah sebagai berikut:

1. Pembentukan Himpunan Fuzzy

a. Himpunan kondisi suhu perancangan derajat keanggotaan variabel fuzzy suhu dibuat pendekatan kepada Peraturan Menteri Kesehatan Republik Indonesia Nomor 1077/Menkes/Per/V/2011[4]

Tabel 1. Himpunann Kondisi Suhu $\left({ }^{\circ} \mathrm{C}\right)$

\begin{tabular}{|c|c|c|}
\hline No & Nama Variable & Nilai Variaabke \\
\hline 1 & Dingin & $0-25$ \\
\hline 2 & Sejuk & $22-27$ \\
\hline 3 & Hangat & $26-30$ \\
\hline 4 & Panas & $29-35$ \\
\hline
\end{tabular}

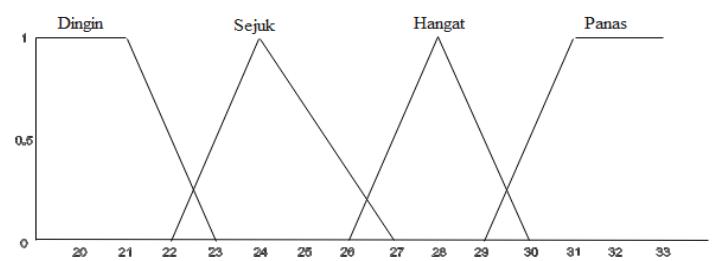

Gambar 1 Himpunann Kondisi Suhu $\left({ }^{0} \mathrm{C}\right)$

Maka dapat dibuat persamaan seperti berikut:

Dingin $(\leq 23)$ 
(x)dingtn $\left\{\begin{array}{c}1: x \leq 21 \\ \frac{23-x}{23-21}: 21<x \leq 23 \\ 0: x>23\end{array}\right.$

Sejuk $(220-270)$

(x)sejuk $\left\{\begin{array}{c}0: x<22 \text { atau } x>27 \\ \frac{x-22}{24-22}: 22 \leq x \leq 24 \\ \frac{27-x}{27-24}: 24<x \leq 27\end{array}\right.$

Hangat $(260-300)$

(x)hongat $\left\{\begin{array}{c}0: x<26 \text { atau } x \geqslant 30 \\ \frac{x-26}{28-26}: 26 \leq x \leq 28 \\ \frac{30-x}{30-28}: 28<x \leq 30\end{array}\right.$

Panas $(290->310)$

(x) sangat panas $\left\{\begin{array}{c}0: x \leq 29 \\ \frac{x-29}{31-29}: 29 \leq x \leq 31 \\ 1: x>31\end{array}\right.$

b. Himpunan kondisi Kelembapan

Penentuan level kelembapan udara diambil dari standar Huminity Guide Higienis Indonesia

Tabel 2. Himpunann Kondisi Kelembapan

\begin{tabular}{|c|c|c|}
\hline No & Nama Variable & Nilai Variaabke \\
\hline 1 & Kering & $0-46$ \\
\hline 2 & Normal & $45-65$ \\
\hline 3 & Basah & $61-75$ \\
\hline
\end{tabular}

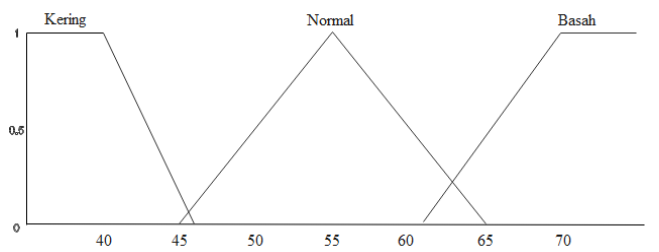

Gambar 2 Himpunann Kondisi

Kelembapan(\%)

Maka dapat dibuat persamaan seperti berikut:

Kering ( $\leq 45,5 \%)$

G)kering $\left\{\begin{array}{c}1: y \leq 40 \\ \frac{45,5-y}{45,5-40}=40<y \leq 45,5 \\ 0: y>45,5\end{array}\right.$

Normal $(45 \%-65 \%)$ (y)normal $\left\{\begin{array}{c}0: x<45 \text { atau } x>65 \\ \frac{y+45}{55-45} ; 45 \leq y \leq 55 \\ \frac{65-y}{65-55} ; 55<y \leq 65\end{array}\right.$

Basah ( >65\%)

(y) busul $\left\{\begin{array}{c}0: y \leq 60,5 \\ \frac{y-60,5}{70-60,5}: 60,5<y \leq 70 \\ 1: y>70\end{array}\right.$

c. Himpunan kondisi suhu

Tabel 3. Himpunann Output Kipas

Angin (\%)

\begin{tabular}{|c|c|c|}
\hline No & Nama Variable & Nilai Variaabke \\
\hline 1 & Berhenti & $0-25$ \\
\hline 2 & Lambat & $22-27$ \\
\hline 3 & Sedang & $26-30$ \\
\hline 4 & Cepat & $29-35$ \\
\hline
\end{tabular}

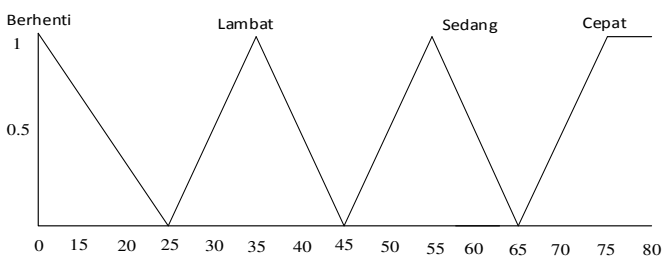

Gambar 3. Derajat Keanggotaan Variabel Duty Cycle Output Kipas Angin

(\%)

Maka dapat dibuat persamaan seperti berikut:

Berhenti

(z)berhenti $\left\{\begin{array}{l}1: z \leq 10 \\ \frac{25-z}{25-10} ; 10<z \leq 25 \\ 0: z>25\end{array}\right.$

Lambat

(z) lambat $\left\{\begin{array}{c}0: x<25 \text { atau } x>45 \\ \frac{z-25}{35-25}: 25 \leq y \leq 35 \\ \frac{45-z}{45-35}: 35<y \leq 45\end{array}\right.$

Sedang

(z) sedang $\left\{\begin{array}{c}0: x<45 \text { atau } x>65 \\ \frac{z-45}{55-45} ; 45 \leq z \leq 55 \\ \frac{65-z}{65-55}: 55<z \leq 65\end{array}\right.$ 


$$
\begin{aligned}
& \text { Cepat } \\
& \text { (z) cepat }\left\{\begin{array}{c}
0: z \leq 65 \\
\frac{z-65}{75-65}: 65<z \leq 75 \\
1: z \leq 75
\end{array}\right.
\end{aligned}
$$

2. Fuzzyfikasi dan Impikasi

Bentuk logika Fuzzy rules yang akan diterapkan adalah berupa $I F \mu \mathrm{p} \_\mathrm{x}=\mathrm{a}$ AND $\mu \mathrm{p} \_\mathrm{y}=\mathrm{b}$ THEN $\mu \mathrm{p} \_\mathrm{z}=\mathrm{c}$, maka yang dicari adalah nilai minimal dari $\mu$ p_x dan $\mu p \_y$. Berdasarkan metode ini, maka aturan pada system otomasi Kipas Angin adalah sebagai berikut :

Aturan 1 : If Suhu DINGIN And Kelembapan KERING Then Kecepatan BERHENTI

Aturan 2 : If Suhu DINGIN And Kelembapan NORMAL Then Kecepatan BERHENTI

Aturan 3 : If Suhu DINGIN And Kelembapan BASAH Then Kecepatan BERHENTI

Aturan 4 : If Suhu SEJUK And Kelembapan KERING Then Kecepatan BERHENTI

Aturan 5 : If Suhu SEJUK And Kelembapan NORMAL Then Kecepatan LAMBAT

Aturan 6 : If Suhu SEJUK And Kelembapan BASAH Then Kecepatan SEDANG

Aturan 7 : If Suhu HANGAT And Kelembapan KERING Then Kecepatan LAMBAT

Aturan 8 : If Suhu HANGAT And Kelembapan NORMAL Then Kecepatan SEDANG

Aturan 9 : If Suhu HANGAT And Kelembapan BASAH Then Kecepatan SEDANG

Aturan 10 : If Suhu PANAS And Kelembapan KERING Then Kecepatan CEPAT

Aturan 11 : If Suhu PANAS And Kelembapan NORMAL Then Kecepatan CEPAT
Aturan 12 : If Suhu PANAS And Kelembapan BASAH Then Kecepatan CEPAT

Jika diketahui nilai $\mathrm{Suhu}=25,60^{\circ} \mathrm{C}$ dan Kelembapan $=96,3 \%$, berdasarkan rumus di atas maka didapatkan hasil setiap level keanggotaan sebagai berikut:

Suhu $(25,60 \mathrm{C})$

$(x)$ dingin $=0$

(x) sejuk $=\frac{27-x}{27-24}=\frac{27-25,6}{27}=0,4667$

( $x$ )hangat $=0$

(x) panas $=0$

Kelembapan $(96,3 \%)$

$(x)$ kering $=0$

(x)normal $=0$

(x)basah $=1$

Kemudian didapatkan implikasi yang berada pada aturan ke-6 yaitu:

If Suhu Sejuk And Kelembapan Basah Then Kecepatan Sedang.

\section{Defuzzyfikasi Kecepatan Kipas Angin}

Kemudian hasil dari fuzzyfikasi tersebut dapat dilihat memasuki rentang sedang untuk output kecepatan kipas.

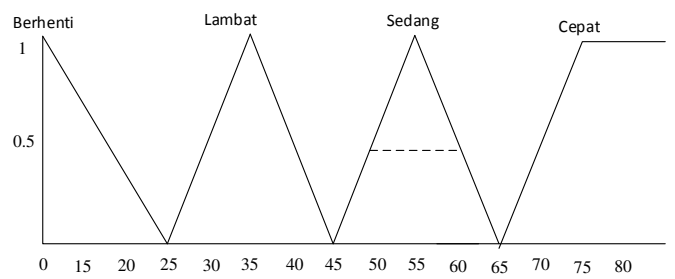

Gambar 4. Derajat Keanggotaan Variabel Duty Cycle Output Kipas Angin

(\%)

$$
\begin{aligned}
\alpha 6 \rightarrow \text { Bawah } & =>0,4667=\frac{x-45}{55-45} \\
& =>0,4667 \times(55-45)=x-
\end{aligned}
$$

45

$$
\begin{aligned}
& \Rightarrow \quad(0,4667 \quad X \quad(55- \\
& \text { 45)) }+45=\mathrm{x}
\end{aligned}
$$$$
=>49,6667=\mathrm{x}
$$

$\alpha 6 \rightarrow$ Atas $=>0,4667=\frac{65-x}{65-55}$

$$
\begin{aligned}
& =>0,4667 \times(65-55)=65-x \\
& =>(0,4667 \times(65-55))=65-x
\end{aligned}
$$




$$
\begin{aligned}
& \Rightarrow>x=65-(0,4667 X(65-55)) \\
& \Rightarrow>x=60,3333
\end{aligned}
$$

Mencari Luas Area
Penerapan Fuzzy Logic Mamdani akan melewati 4 tahapan yaitu: a. Himpunana Kondisi waktu Tabel 4. Himpunann Kondisi $\operatorname{Suhu}\left({ }^{\circ} \mathrm{C}\right)$

\begin{tabular}{|c|c|c|}
\hline No & Nama Variable & Nilai Variabke \\
\hline 1 & Dini Hari & $0: 00-7: 00$ \\
\hline 2 & Pagi-Sore & $6: 00-19: 00$ \\
\hline 3 & Malam & $26-30$ \\
\hline 4 & Malam-Istirahat & $29-35$ \\
\hline
\end{tabular}
49,6667)

$$
\begin{aligned}
& =4,9778 \\
\mathrm{~A}_{3} & =\frac{\text { AlasA }_{3} * \operatorname{TinggiA}_{3}}{2}=\frac{)(60,3333-49,6667) * 0,4667}{2}=1,0889
\end{aligned}
$$

Menghitung Momentum

$$
\begin{aligned}
& M_{1}=\int_{45}^{49,6667}(0,1 z-4,5) z d z=\int_{45}^{49,6667}\left(0,1 z^{2}-4,5 z\right) d z \\
& \left.=0,333 z^{3}-2,25^{2}\right]_{45}^{49,6667} \\
& =\left((0,1 / 3)^{*}(49,6667)^{3}-(4,5 / 2) \mathrm{X}(49,6667)^{2}\right)-\left((0,1 / 3) *(45)^{3}-(4,5 / 2) \mathrm{X}(45)^{2}\right) \\
& =52,388 \\
& M_{2}=\int_{49,6667}^{60,3333}(0,4667) z d z=\int_{49,6667}^{60,3333}(0,4667) d z \\
& \left.=0,275 z^{2}\right]_{49,6667}^{60,3333} \\
& =\left(0,2333 *(60,3333)^{2}\right)-\left(0,2333 *(49,6667)^{2}\right) \\
& =273,778 \\
& M_{3}=\int_{60,3333}^{65}(6,5-0,1 z) z d z=\int_{60,3333}^{65}\left(6,5-0,1 z^{2}\right) d z \\
& \left.=3,25 z^{2}-0,033 z^{3}\right]_{60,3333}^{65} \\
& =\left(\left(3,25 \mathrm{x}(65)^{2}\right)-\left(0,033 \mathrm{x}(65)^{3}\right)\right)-\left(\left(3,25 \mathrm{x}(60,3333)^{2}\right)-\left(0,033 \mathrm{X}(60,3333)^{3}\right)\right)
\end{aligned}
$$$$
=67,390
$$$$
Z^{*}=\frac{M 1+M 2+M 3}{A 1+A 2+A 3}
$$$$
=\frac{52,388+273,778+67390}{1,0889+4,9778+1,0889}
$$$$
=55
$$

Nilai $\mathrm{Z}^{*}$ ini merupakan ukuran output dari kerja kipas angin yaitu sebesar 55\% dan termasuk anggota himpunanan kecepatan kipas angin "Sedang"

\section{Implementasi Kontrol Lampu}

Implementasi Kontrol Lampu dengan Fuzzy mamdani adalah sebagai berikut::

1. Pembentukan Himpunan Fuzzy

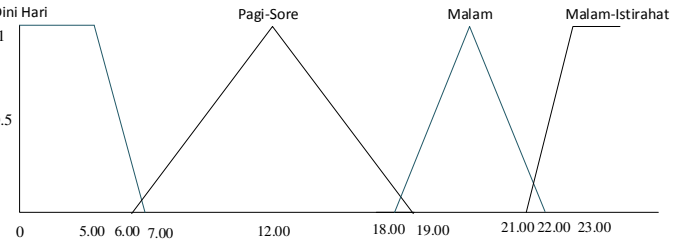

\section{Gambar 5. Himpunann Kondisi Waktu}

Maka dapat dibuat persamaan seperti berikut:

Dini Hari $(\leq 6.00)$

(y)dini hari $\left\{\begin{array}{c}1: y \leq 5 \\ 7-y ; 5<y \leq 7 \\ 0: y>7\end{array}\right.$

Pagi-Sore $(6.00-18.00)$

(y) PS $\left\{\begin{array}{c}0: x<6 \text { atou } x>19 \\ \frac{y-6}{12-6} ; 6 \leq y \leq 12 \\ \frac{19-y}{19-12}: 12<y \leq 19\end{array}\right.$

Malam $(18.00-22.00)$

(y) Malam $\left\{\begin{array}{c}0: x<18 \text { atau } x>22 \\ \frac{y-18}{20-18} ; 18 \leq y \leq 20 \\ \frac{22-y}{22-20} ; 20<y \leq 22\end{array}\right.$

Malam-Istirahat ( $>21$ )

$$
\text { (y) basah }\left\{\begin{array}{c}
0: y \leq 21 \\
\frac{y-21}{23-21}: 21<y \leq 23 \\
1: y>23
\end{array}\right.
$$

b. Himpunanan Intensitas Cahaya Masuk

Tabel 5. Himpunann Kondisi Intensitas Cahaya Masuk (lux)

\begin{tabular}{|c|c|c|}
\hline No & Nama Variable & Nilai Variaabke \\
\hline 1 & Gelap & $0-25$ \\
\hline 2 & Sangat Redup & $20-100$ \\
\hline
\end{tabular}




\begin{tabular}{|c|c|c|}
\hline 3 & Redup & $95-200$ \\
\hline 4 & Terang & $195-250$ \\
\hline
\end{tabular}

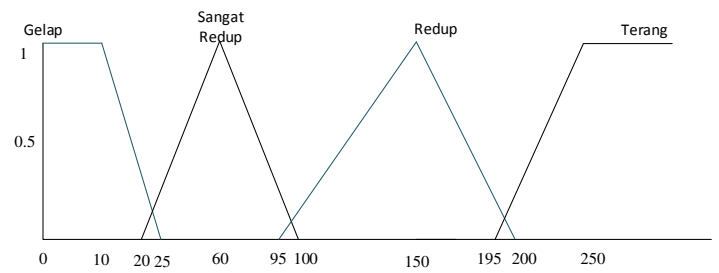

Gambar 6. Himpunann Kondisi

Intensitas Cahaya Masuk (lux)

Maka dapat dibuat persamaan

seperti berikut:

Gelap $(\leq 20 \operatorname{lux})$

(x)gelap $\left\{\begin{array}{c}1: x \leq 10 \\ \frac{25-x}{25-10}: 10<x \leq 25 \\ 0: x>25\end{array}\right.$

Sangat Redup (20lux - $100 \operatorname{lux}$ )

(x) sangat redup $\left\{\begin{array}{l}0: x<20 \text { atou } x>100 \\ \frac{x-20}{60-20} ; 20 \leq x \leq 60 \\ \frac{100-x}{100-60} ; 60 \leqslant x \leq 100\end{array}\right.$

Redup (100 lux - $200 \operatorname{lux})$

(x)redup $\left\{\begin{array}{c}0: x<95 \text { atau } x>150 \\ \frac{x-95}{150-95}: 95 \leq x \leq 150 \\ \frac{200-x}{200-150}: 150<x \leq 200\end{array}\right.$

Terang (>=200 lux)

(x)terang $\left\{\begin{array}{c}0: x \leq 195 \\ \frac{x-195}{250-195}: 195 \leq x \leq 250 \\ 1: x>250\end{array}\right.$

c. Himpunan Output Lampu

Tabel 6. Himpunann Output Lampu (lux)

\begin{tabular}{|c|c|c|}
\hline No & Nama Variable & Nilai Variaabke \\
\hline 1 & Mati & $0-10$ \\
\hline 2 & Redup & $10-75$ \\
\hline 3 & Terang & $75-130$ \\
\hline 4 & Sangat Terang & $130-145$ \\
\hline
\end{tabular}

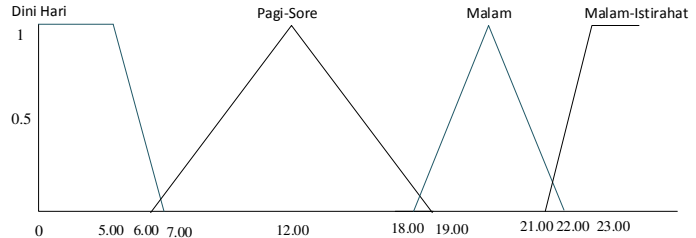

Gambar 7. Himpunann Kondisi Waktu

Maka dapat dibuat persamaan seperti berikut:

Mati

(z)mati $\left\{\begin{array}{c}1: z \leq 10 \\ \frac{10-z}{10-0}: 0<z \leq 10 \\ 0: z>10\end{array}\right.$

Redup

(z)redup $\left\{\begin{array}{c}0: x<10 \text { atau } x>70 \\ \frac{z-10}{30-10}=10 \leq y \leq 30 \\ \frac{75-z}{75-30}: 30<y \leq 75\end{array}\right.$

Terang

(z)terang $\left\{\begin{array}{c}0: x \leqslant 75 \text { atcu } x>135 \\ \frac{z-75}{110-75}: 75 \leq z \leq 110 \\ \frac{130-z}{130-110}: 110<z \leq 130\end{array}\right.$

Sangat Terang

(z) sangat terang $\left\{\begin{array}{l}0: z \leq 130 \\ \frac{z-130}{145-130} ; 130<z \leq 145 \\ 1: z \leq 145\end{array}\right.$

2. Fuzzyfikasi dan Impikasi

Bentuk logika Fuzzy rules yang akan diterapkan adalah berupa $I F \mu \mathrm{p} \_\mathrm{x}=\mathrm{a}$ AND $\mu \mathrm{p} \_\mathrm{y}=\mathrm{b}$ THEN $\mu \mathrm{p} \_\mathrm{z}=\mathrm{c}$, maka yang dicari adalah nilai minimal dari $\mu$ p_x dan $\mu$ p_y. Berdasarkan metode ini, maka aturan pada system otomasi Kipas Angin adalah sebagai berikut :

Aturan 1 : If Jam DINI HARI And Cahaya GELAP Then Level REDUP

Aturan 2:If Jam DINI HARI And Cahaya SANGAT REDUP Then Level MATI

Aturan 3 : If Jam DINI HARI And Cahaya REDUP Then Level MATI

Aturan 4 : If Jam DINI HARI And Cahaya TERANG Then Level MATI 
Aturan 5 : If Jam PAGI-SORE And Cahaya GELAP Then Level TERANG

Aturan 6 : If Jam PAGI-SORE And Cahaya SANGAT REDUP Then Level REDUP

Aturan 7 : If Jam PAGI-SORE And Cahaya REDUP Then Level REDUP

Aturan 8 : If Jam PAGI-SORE And Cahaya TERANG Then Level MATI

Aturan 9 : If Jam MALAM And Cahaya GELAP Then Level SANGAT TERANG

Aturan 10 : If Jam MALAM And Cahaya SANGAT REDUP Then Level SANGAT TERANG

Aturan 11 : If Jam MALAM And Cahaya REDUP Then Level SANGAT TERANG

Aturan 12 : If Jam MALAM And Cahaya TERANGThen Level TERANG

Aturan 13 : If Jam MALAM ISTIRAHAT And Cahaya GELAP Then Level REDUP Aturan 14 : If Jam MALAM ISTIRAHAT And Cahaya SANGAT REDUP Then Level MATI

Aturan 15 : If Jam MALAM ISTIRAHAT And Cahaya REDUP Then Level MATI Aturan 16: If Jam MALAM ISTIRAHAT And Cahaya TERANG Then Level MATI

Jika diketahui Intensitas Cahaya Masuk adalah 18 lux dan Waktu pukul 1:67 maka:

Intensitas Cahaya Masuk(18 lux):

(x) gelap $\left\{\frac{25-18}{25-10}=0,4667\right.$

(x) sangatredup $=0$

(x) redup $=0$

(x)terang $=0$

Waktu(1:67):

(x) dinihari $=0$

(x) pagi - sore $=0$

(x) malam $=0$

(x) malamistirahat $=0$

Kemudian didapatkan implikasi yang berada pada aturan ke-1 yaitu:

If Jam DINI HARI And Cahaya GELAP Then Level REDUP

3. Defuzzyfikasi Intensitas Lampu
Berdasarkan

perhitungan fuzzyfikasi, maka terdapat implikasi di rule 1 :

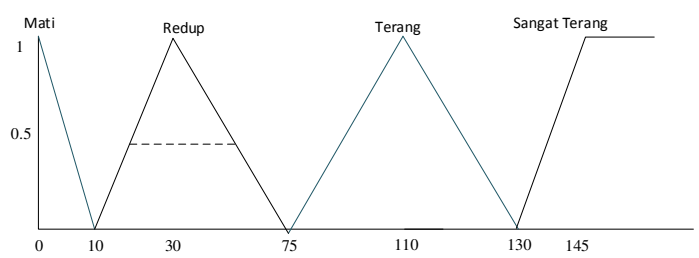

Gambar 8. Derajat Keanggotaan Intensitas Lampu (lux)

$$
\begin{aligned}
\boldsymbol{\alpha}_{1} \rightarrow \text { Bawah } & =>0,4667=\frac{x-10}{30-10} \\
& =>0,4667 \times(30-10)=\mathrm{x}-
\end{aligned}
$$

10

$$
\Rightarrow \quad(0,4667 \quad X \quad(30-
$$

10) $)+10=\mathrm{x}$

$$
\begin{aligned}
& =>19,33=\mathrm{x} \\
\text { Atas } \quad & =>0,4667=\frac{75-x}{75-30} \\
& =>0,4667 \times(75-30)=75-\mathrm{x} \\
& =>(0,4667 \times(75-30))=75-
\end{aligned}
$$

$\mathrm{X}$

$$
=>x=75-(0,4667 x(75-
$$

30))

$$
\Rightarrow \mathrm{x}=54
$$

Mencari Luas Area

$$
\begin{aligned}
& \mathrm{A}_{1}=\frac{\text { AlasA }_{1} * \text { TinggiA }_{1}}{2}=\frac{(19,333-10) * 0,4667}{2}=2,1778 \\
& \mathrm{~A}_{2}=\text { panjang } \mathrm{A}_{2} * \text { lebar } \mathrm{A}_{2}=\text { (54- } \\
& 19,3333) * 0,4667 \\
& =16,1778 \\
& \mathrm{~A}_{3}=\frac{\text { AlasA }_{3} * \text { Ting giA }_{3}}{2}=\frac{(75-54) * 0,4667}{2}=4,9
\end{aligned}
$$

Menghitung Momentum

$$
\begin{aligned}
& M_{1}=\int_{10}^{19,3333}(0,05 z-0,5) z d z=\int_{75}^{19,3333}\left(0,05 z^{2}-0,5 z\right) d z \\
& \left.=0,0167 z^{3}-2,25^{2}\right]_{75}^{19,3333} \\
& =\left(0,0167 *(19,3333)^{3}-0,25 X(19,3333)^{2}\right)-\left(0,0167 X^{*}(10)^{3}-0,25 X(10)^{2}\right) \\
& =35,328
\end{aligned}
$$




$$
\begin{array}{ll}
M_{2}=\int_{19,3333}^{54}(0,4667) z d z=\int_{19,3333}^{54}(0,4667) d z & 2 . \mathrm{A} \\
\left.=0,2333 z^{2}\right]_{19,3333}^{54} & \text { men } \\
=\left(0,2333 *(54)^{2}\right)-\left(0,2333 *(19,3333)^{2}\right) & \text { yang } \\
=593,1852 & \text { faktor } \\
M_{3}=\int_{54}^{75}(1,6667-0,0222 z) z d z=\int_{54}^{75}\left(1,6667-0,222 z^{2}\right) d z & \\
\left.=0,8333 z^{2}-0,0074 z^{3}\right]_{36,667}^{45} & \\
=\left(\left(0,8333 \times(75)^{2}\right)\right)-\left(\left(0,0074 \times(75)^{3}\right)-\left(\left(0,8333 \times(54)^{2}\right)-0,0074 \mathrm{X}(54)^{3}\right)\right) \\
=298,9
\end{array}
$$$$
Z^{*}=\frac{M 1+M 2+M 3}{A 1+A 2+A 3}
$$$$
=\frac{35,328+593,1852+298,9}{2,1778+16,1778+4,9}
$$$$
=39,88
$$

Nilai $Z^{*}$ ini merupakan ukuran lux dari output intensitas cahaya lampu 39,88 lux dan termasuk anggota himpunanan kecepatan kipas angin "Redup"

\section{SIMPULAN}

Dari Penelitian ini dapat ditarik sebuah kesimpulan berupa:

1. Dalam menentukan persamaan himpunan fuzzy diperlukan data berupa rentang dari masing-masing kondisi.
2. Algoritma Fuzzy Logic Mamdani dapat menghasilkan jawaban akan suatu kondisi yang tidak pasti melalui perhitungan faktorfaktor yang ada pada kondisi tersebut.

\section{DAFTAR PUSTAKA}

[1] Imam Ibnu Mukti. "Kapal Cerdas Berbasis Mikrokontroller ATMega328," Thesis. Universitas Muhammadiyah Purwokerto. Purwokerto, Jawa Tengah. 2018.

[2] Nadya Febriany, Fitriani Agustina, Rini Marwati, "Aplikasi Metode Fuzzy Mamdani Dalam Penentuan Stastus Gizi Dan Kebutuhan Kalori Harian Balita Menggunakan Software Matlab," Vol 5. ,No. 1 , 2017.

[3] J. Jantzen, "Tutorial On Fuzzy Logic," vol. 1998, no. 98-E-868 (logic), pp. 1-20, 1998.

[4] M. Kesehatan and R. Indonesia, "Peraturan Mentri Kesehatan Indonesia No 1077/Menkes/PER/2011," 2011.

[5] S. Wirjohamidjojo and Y. S. Swarinoto, "Praktek meteorologi pertanian,” p. 191 hal., 2007. 